\title{
Characteristics and Visual Prognosis of Pediatric Open Globe Injury in Shanghai, China
}

\author{
Yue Guo ${ }^{a}$ Yu Guo ${ }^{a}$ Ruiping Gu ${ }^{a}$ Qian Yang ${ }^{a}$ Ke Zhu ${ }^{a}$ Qinmeng Shu \\ Dekang Gan a, b, c \\ aDepartment of Ophthalmology, Eye and ENT Hospital of Fudan University, Shanghai, PR China; \\ bShanghai Key Laboratory of Visual Impairment and Restoration, Shanghai, PR China; 'Key Laboratory of \\ Myopia of State Health Ministry, Shanghai, PR China
}

\section{Keywords}

Open globe injury · Child eye health · Clinical trial

\begin{abstract}
Introduction: The aim of the study was to describe the characteristics of open globe injury (OGI) and the relationship between the complications and visual outcomes in children with this type of injury. Methods: This was a retrospective chart review of 1,664 children, under the age of 16 years, who were hospitalized for OGI between January 1, 2007, and December 31, 2015. Each patient's age, sex, cause and agent of injury, complications, visual acuity, and classification of ocular trauma were collected for review and analysis. Results: The mean age was $5.6 \pm 3.4$ years. Right eyes were particularly vulnerable to injury (right eye:left eye ratio $=1.2: 1$ ). Traumatic cataract was the most common complication. The average initial and final best corrected visual acuity were logarithm of the minimum angle of resolution (logMAR) $2.04 \pm$ 0.78 and logMAR $1.74 \pm 0.88$, respectively. Logistic regression analysis showed that hyphema (odds ratio $[O R]=1.850$ ), iris prolapse $(O R=1.702)$, vitreous hemorrhage $(O R=9.703)$,
\end{abstract}

retinal detachment $(O R=11.938)$, endophthalmia $(O R=$ $5.377)$, intraocular foreign body $(O R=3.346)$, and initial visual acuity $<0.05(O R=9.017)$ were risk factors for visual acuity $<0.05$ at hospital discharge. Conclusion: OGl was most frequent in preschool children and boys. Right eyes were more vulnerable than left eyes. Poor visual outcomes were associated with hyphema, iris prolapse, vitreous hemorrhage, retinal detachment, endophthalmia, intraocular foreign body, and an initial visual acuity $<0.05$.

(c) 2022 The Author(s).

Published by S. Karger AG, Basel

\section{Background}

Ocular trauma is one of the most important causes of ophthalmic hospitalization and can lead to vision loss and blindness. Pediatric eye injuries account for a large proportion of all ocular trauma [1]. The annual incidence of pediatric ocular trauma is 15.2 per 100,000 children in the population [2]. Without timely therapeutic intervention, pediatric ocular trauma may result in visual impairment and even blindness [3]. For pediatric patients, an unclear
C 2022 The Author(s).

Published by S. Karger AG, Basel

This is an Open Access article licensed under the Creative Commons Attribution-NonCommercial-4.0 International License (CC BY-NC) (http://www.karger.com/Services/OpenAccessLicense), applicable to the online version of the article only. Usage and distribution for commercial purposes requires written permission.
Correspondence to:

Dekang Gan, dekang.gan@fdeent.org 
mechanism of injury and poor patient cooperation during eye examinations make the clinical course more complex and yield less information than is the case for adult patients [4]. Open globe injury (OGI) is a severe pathological condition resulting from ocular trauma. It is defined as a full-thickness laceration of the cornea, sclera, or both that has damaged the eyeball structure [5-7].

Several previous studies have noted that most cases of OGI result in visual impairment $[8,9]$ and monocular blindness [10]. Existing research has reported the incidence of OGI as 2-3.8 per 100,000 in developed countries $[11,12]$. OGI in children generates a significant socioeconomic cost and leads to serious visual impairment and even long-term disability. Despite public health campaigns designed to prevent eye injuries, OGI still occurs.

Limited epidemiological studies of OGI have been conducted in developing countries in Asia in recent years. Previous work has aimed to identify the causes of OGI and clarify the nature of these injuries in the population, informing educational and legislative efforts to minimize eye injuries $[10,13]$. To provide a more comprehensive understanding of the characteristics of OGI and the risk factors for its poor visual prognosis, we examined pediatric OGI in Shanghai, China.

\section{Methods}

\section{Subjects}

This was a retrospective study of children aged $<16$ years who had been diagnosed with OGI and admitted to the Eye and Ear, Nose, and Throat (EENT) Hospital of Fudan University, Shanghai, China, for this condition between January 1, 2007, and December 31,2015 . This study complied with the tenets of the Declaration of Helsinki and its amendments and was approved by the Ethics Committee of the EENT Hospital of Fudan University. Signed informed consent was obtained from all their parents or guardians. Following previous research, OGI was defined as a break in the structural integrity of either the cornea or sclera, creating a connection between the intraocular contents and the external environment [14].

\section{Data}

Demographic and clinical data on 1,664 patients were obtained from the database platform for ophthalmic research of the EENT Hospital of Fudan University [15]. The method used to select patients was similar to that used in our previously reported study [15]. Children aged $0-16$ years with OGI who were admitted to our hospital between January 2007 and December 2015 were included. Patients with congenital eye diseases or other types of eye trauma were excluded. We then integrated the different kinds of data collected from different medical record systems using a big data platform. These data included each patient's age, sex, cause and agent of injury, complications in the anterior and posterior segments of the eye, visual acuity at presentation and at hospital discharge, and

Characteristics of Pediatric Open Globe

Injury Patients the classification of ocular trauma. The Ocular Trauma Score [16] was also recorded. OGI was classified as penetration, rupture, perforation, or the presence of an intraocular foreign body using the standardized international classification of ocular trauma. In accordance with previous research [17], the study population was subdivided into preschool (0-6 years), primary school (7-12 years), and secondary school children (13-16 years) based on the distinct differences in behavior and types of education in these three age groups. The causes of their OGI were categorized by the causative object. If the causative object was not described in the database, it was classified as "unknown." We described the characteristics and initial findings after OGI for all the patients included. We then analyzed the relationship between the final visual acuity and initial predictors only in those children who were able to state their visual acuity, in the results associated with ocular damage. Younger children cannot describe their vision, which could influence the accuracy of our analysis. Therefore, children without complete visual information and younger children without visual acuity data were excluded. According to the World Health Organization's standard of blindness and reports of the disease burden posed by blindness, we selected a final visual acuity of $<0.05$ as the cutoff value with which to analyze the relationship between the complications of OGI and visual prognosis [18-20]. Thus, to analyze the relationship between complications and visual prognosis, the patient's final visual acuity was classified as $<0.05$ or $\geq 0.05$. Logistic regression analysis was used to predict a final visual acuity of $<0.05$, and patients with a final visual acuity of $\geq 0.05$ were used as the reference group.

\section{Statistical Analyses}

Statistical analyses were performed using SPSS version 22.0 (IBM Corporation, Armonk, NY, USA). Logarithm of the minimum angle of resolution (logMAR) units were used to express average visual acuity. Means and standard deviations were used to describe the continuous variables. The categorical variables were described using either percentages or rates. Comparisons between two groups of categorical variables were performed using the $\chi^{2}$ test or Fisher's exact test. The Kruskal-Wallis test was used to compare differences in continuous variables. Correlations were assessed with Spearman's correlation analysis. Binary logistic regression analyses were used to evaluate the relationships between the patient variables at presentation and the final visual outcome. $p$ values of $<0.05$ were considered statistically significant.

\section{Results}

\section{Demographic Information}

In total, 1,214 of the patients with OGI were boys $(73 \%)$ and $450(27 \%)$ were girls (male-to-female ratio = 2.7:1). There was a predominance of boys across the three age groups in our patient cohort. Right eyes were particularly vulnerable to injury (right eye:left eye ratio $=1.2: 1$ ), and 7 patients presented with bilateral OGI. The mean age of patients admitted to the hospital was $5.6 \pm 3.4$ years $(6 \pm 3.8$ years for boys and $4.9 \pm 3.2$ years for girls). The majority of pediatric patients with OGI were in the pre- 
Table 1. Characteristics of patients

\begin{tabular}{llll}
\hline Characteristics & Male, $n(\%)$ & Female, $n(\%)$ & Total \\
\hline $\begin{array}{l}\text { Laterality of eyes } \\
\quad \text { Right }\end{array}$ & $643(72.2)$ & $247(27.8)$ & 890 \\
$\quad$ Left & $565(73.7)$ & $202(26.3)$ & 767 \\
$\quad$ Both & $6(85.7)$ & $1(14.3)$ & 7 \\
Age group & & & 0 \\
$\quad$ 0-6 & $751(69.5)$ & $329(30.5)$ & 1,080 \\
7-12 & $373(77.2)$ & $110(22.8)$ & 483 \\
13-16 & $90(89.1)$ & $11(10.9)$ & 101 \\
$\quad$ Average & $6 \pm 3.8$ & $4.9 \pm 3.2$ & $5.6 \pm 3.4$ \\
Type of OGls & & & \\
$\quad \begin{array}{l}\text { Penetrating } \\
\text { Rupture } \\
\quad \text { Perforating }\end{array}$ & $947(71.7)$ & $374(28.3)$ & $1,321(79.4)$ \\
$\quad$ Intraocular foreign body & $171(76)$ & $54(24)$ & $225(13.5)$ \\
\hline Total & $10(83.3)$ & $2(16.7)$ & $12(0.7)$ \\
\hline
\end{tabular}

school (0-6 years) age group. Table 1 presents the demographic characteristics and injury classification for children with OGI. Penetrating injuries (79.4\%) were the most common type of injury in these patients.

Among the different mechanisms of eye injury, the sharp instruments involved included scissors, fruit knives, pencil knives, nail clippers, pencils, pens, ballpoint pens, glass, beer bottle glass fragments, pieces of glass, plants, metal wire, needles, and bamboo sticks. The agents of blunt force injuries included clubs (wooden stick), steel tubes, brooms, clothes hangers, fishing rods, toys, and body collision. The most common cause of injury was a sharp instrument ( $n=1,087,65.3 \%)$, followed by blunt force injury and explosive injury. Other causes of eye injury are shown in online supplementary Table 1 (see www.karger.com/doi/10.1159/000523814 for all online suppl. material). The most common objects causing the injury were scissors $(n=360,21.6 \%)$ (Table 2$)$. The top three objects causing injury differed across the three age groups. For children aged 0-6 years, scissors, glass, and firecrackers were the most common injury-causing objects. In the 7-12 years age group, the most frequent causative object was scissors, followed by firecrackers and pencils. Patients aged 13-16 years were predominantly injured by glass, firecrackers, or plants (online suppl. Table 2).

In this cohort of pediatric patients with OGI, traumatic cataract $(40.4 \%)$ was the most common complication noted in the initial findings. Other common anterior segment injuries included iris prolapse (28.9\%), hyphema (19.5\%), iridodialysis (3.3\%), and hypopyon (2.0\%). Posterior segment injuries included endophthalmia (22.7\%),
Table 2. Top ten causes of eye injuries

\begin{tabular}{ll}
\hline Top ten of injurers & Cases, $n(\%)$ \\
\hline Scissor & $360(21.6)$ \\
Firecracker & $104(6.2)$ \\
Pencil & $94(5.6)$ \\
Glass & $82(4.9)$ \\
Plants & $72(4.3)$ \\
Metal wire & $65(3.7)$ \\
Club (wooden stick) & $61(3.7)$ \\
Needle & $51(3.0)$ \\
Knife & $50(3.0)$ \\
Bamboo stick & $42(2.5)$ \\
\hline
\end{tabular}

retinal detachment (13.3\%), vitreous hemorrhage (12.4\%), intraocular foreign body (6.6\%), and choroidal detachment (6.4\%).

\section{Associated Ocular Damage}

Some of the children were too young to cooperate in a visual examination, and the medical records of some patients were incomplete in terms of the visual examination. After all incomplete records and records of uncooperative patients were excluded, the initial and final best corrected visual acuities (BCVAs) were documented for 732 patients. The average initial and final BCVA were $\log$ MAR $2.04 \pm 0.78$ and $\log$ MAR $1.74 \pm 0.88$, respectively. Visual acuity at presentation in the hand motion range accounted for the largest percentage of eye injuries (29.5\%), followed by the light perception range (28.4\%) (online suppl. Table 3 ). We further explored the 
Table 3. Univariate analysis of prognosis with visual acuity $<0.05$ or $\geq 0.05$

\begin{tabular}{|c|c|c|c|c|}
\hline Factors & Final VA $<0.05$ & Final VA $\geq 0.05$ & $p$ value & OR \\
\hline \multicolumn{5}{|l|}{ Gender } \\
\hline Female & $97(60.2)$ & $64(39.8)$ & \multirow{2}{*}{0.098} & \multirow{2}{*}{1.355} \\
\hline Male & $384(67.3)$ & $187(32.7)$ & & \\
\hline \multicolumn{5}{|l|}{ Age } \\
\hline $0-6$ & $168(65.1)$ & $90(34.9)$ & \multirow{3}{*}{0.03} & \\
\hline $7-12$ & $245(63.3)$ & $142(36.7)$ & & \\
\hline 13-16 & $68(78.2)$ & $19(21.8)$ & & \\
\hline Leukoma & $23(54.8)$ & $19(45.2)$ & 0.124 & 0.613 \\
\hline RAPD & $119(66.5)$ & $60(33.5)$ & 0.803 & 1.046 \\
\hline Iridodialysis & $26(68.4)$ & $12(31.6)$ & 0.718 & 1.138 \\
\hline Iris prolapse & $108(63.5)$ & $62(36.5)$ & 0.494 & 0.883 \\
\hline Hypopyon & $16(100)$ & $0(0)$ & 0.003 & 0.649 \\
\hline Hyphema & $103(84.4)$ & $19(15.6)$ & $<0.001$ & 3.327 \\
\hline Trauma cataract & $333(68.1)$ & $156(31.9)$ & 0.054 & 1.37 \\
\hline Vitreous hemorrhage & $116(95.1)$ & $6(4.9)$ & $<0.001$ & 12.977 \\
\hline Retinal detachment & $119(96.0)$ & $5(4.0)$ & $<0.001$ & 16.173 \\
\hline Choroidal detachment & $48(98.0)$ & $1(2.0)$ & $<0.001$ & 27.714 \\
\hline Endophthalmia & $146(84.9)$ & $26(15.1)$ & $<0.001$ & 3.772 \\
\hline Intraocular foreign body & $52(80.0)$ & $13(20.0)$ & 0.011 & 2.215 \\
\hline Atrophy of eyeball & $6(100)$ & $0(0)$ & 0.076 & 0.654 \\
\hline Initial VA $<0.05$ & $142(44.2)$ & $179(55.8)$ & $<0.001$ & 10.604 \\
\hline \multicolumn{5}{|l|}{ Type of injury } \\
\hline Penetrating & $288(52.0)$ & $266(48.0)$ & \multirow{4}{*}{$<0.001$} & \\
\hline Perforating & $5(100.0)$ & $0(0)$ & & \\
\hline Intraocular foreign body & $53(81.5)$ & $12(18.5)$ & & \\
\hline Rupture & $65(60.2)$ & $43(39.8)$ & & \\
\hline
\end{tabular}

RAPD, related afferent pupillary defect.

Table 4. Logistic regression analysis of prognosis with visual acuity $<0.05$ or $\geq 0.05$

\begin{tabular}{llc}
\hline Factors & OR $(95 \% \mathrm{Cl})$ & $p$ value \\
\hline Hyphema & $1.850(1.004,3.411)$ & 0.049 \\
Iris prolapse & $1.702(1.054,2.747)$ & 0.029 \\
Vitreous hemorrhage & $9.703(3.887,24.225)$ & $<0.001$ \\
Retinal detachment & $11.938(4.468,31.899)$ & $<0.001$ \\
Endophthalmia & $5.337(3.192,8.925)$ & $<0.001$ \\
Intraocular foreign body & $3.346(1.461,7.661)$ & 0.004 \\
Initial VA <0.05 & $9.017(5.506,14.768)$ & $<0.001$ \\
\hline
\end{tabular}

For the multivariate analysis, visual acuity on leaving hospital $\geq 0.05$ was used as the reference, $x^{2}=4.695, p=0.454$. Differences were considered statistically significant at $p \leq 0.05$.

visual outcomes after different types of injury (online suppl. Table 4). In the group with final BCVA $\geq 0.05$, the percentage of penetrating injuries was $29.2 \%$, whereas ruptures accounted for $3.1 \%$, intraocular foreign body

Characteristics of Pediatric Open Globe Injury Patients for $1.8 \%$, and perforation for $0.1 \%$. The final visual acuities in the Ocular Trauma Score (OTS) study and in the present study are presented in online supplementary Table 5 .

The final visual outcomes were classified as visual acuity of $<0.05$ or $\geq 0.05$. We performed both univariate and binary logistic regression analyses with a final visual acuity of $<0.05$ (vs. $\geq 0.05$ ) as the dependent variable. There were statistically significant differences between the two final visual acuity groups ( $<0.05 \mathrm{vs.} \geq 0.05)$ in terms of sex, hypopyon, hyphema, vitreous hemorrhage, retinal detachment, choroidal detachment, endophthalmia, intraocular foreign body, and visual acuity $<0.05$ at presentation (Table 3). The logistic regression analysis showed that hyphema (odds ratio $[\mathrm{OR}]=1.850)$, iris prolapse (OR $=1.702)$, vitreous hemorrhage $(\mathrm{OR}=9.703)$, retinal detachment $(\mathrm{OR}=11.938)$, endophthalmia $(\mathrm{OR}=5.377)$, intraocular foreign body $(\mathrm{OR}=3.346)$, and initial visual $<0.05(\mathrm{OR}=9.017)$ were risk factors for a visual acuity of $<0.05$ at hospital discharge (Table 4 ). 


\section{Discussion}

Pediatric OGI is associated with long-term visual impairment and socioeconomic burden [1]. A lack of awareness of its prevention and immediate treatment increases the risk of complications and visual impairment in cases of OGI [21]. Children with OGI are likely to require timely ophthalmological intervention. The analysis of clinical characteristics presented in this article may help predict the visual prognosis in cases of pediatric OGI. This retrospective study summarized the demographic characteristics of pediatric patients with OGI and analyzed the complications related to visual acuity at hospital discharge in this group.

Our results are consistent with the previously published findings that OGI is more frequent in boys than in girls and affects the right eye more often than the left eye $[22,23]$. The sex distribution of our study cohort was also consistent with that in previous studies, where the maleto-female ratios were $2.6: 1$ to $3.4: 1[24,25]$. One previous study [26] noted that the right eye is more prone to injury because most children are dextromanual. The average age of patients in this study was lower than that reported in previous studies $[24,27]$. We found that OGI occurred at a high rate in the preschool ( $0-6$ years) age group for both sexes. This finding differs from a study in developed countries [26]. We found that preschool children were especially vulnerable to OGI in China. However, Al-Mahdi et al. [24] described that, in the early years of life, children are closely supervised by adults, which contributes to the low rate of OGI. In another study at our hospital, researchers found that ocular trauma was more severe and had a worse visual prognosis in the left-behind children because of a lack of care and delayed treatment [28]. However, the contribution of insufficient supervision has been challenged, particularly because during the COVID pandemic, when children were likely to have been at home and therefore more closely supervised, OGI actually increased.

In our study, penetrating injuries accounted for $76.6 \%$ of OGI. This finding is similar to AlDahash's results [27], but our findings for the incidence rates of perforating and rupture injuries were lower in the present study than those reported in AlDahash's study. The prevalence of an intraocular foreign body has decreased in recent years according to this finding. One study of OGI in all age groups (1-80 years) found that intraocular foreign bodies and penetrating injuries accounted for $42.1 \%$ and $36.5 \%$ of all OGI, respectively [29]. Our findings for pediatric OGI differed from this previous report among all age groups.
Existing work indicates that there are regional differences in the objects that cause ocular trauma. Metallic objects such as forks, nails, and wires were the most common causes of eye injuries in children in Turkey [30]. A study in Upper Egypt found that wood, stones, and projectiles were common objects causing eye trauma [8]. Previously published results have varied regarding the age-specific frequency of specific injury-causing objects. We found that scissors, glass, and firecrackers were the most common causes of OGI among preschool children, but pencils were among the top three causative objects among primary school children. This difference probably arises because students begin to learn to write with pencils at the primary school level. In the secondary school group, scissors were not among the most common objects causing injury. The most common cause of OGI in this group was glass, followed by firecrackers and plants, indicating that these older children have a wider range of activities compared with preschool children. Scissors should be kept out of reach of children in preschool and primary school, and parents and teachers should emphasize safety in the use of pencils for primary school children. Firecrackers were the second most common cause of injury in the full study cohort. Karin [31] showed that eye injuries from fireworks were much more frequent among boys. A study of childhood ocular trauma in New Zealand reported that $55 \%$ of children with visual acuity $\leq 0.1$ had suffered injuries from fireworks [32]. These previous findings, together with the findings of the present study, should prompt the government to ban the use of firecrackers by unsupervised children and to strengthen health education and safety strategies targeting the unsafe handling of fireworks. In a previous study, we found firework injuries accounted for the largest proportion of injuries in February (35.6\%), around the Chinese Spring Festival [15]. That study included data from the period from January 1, 2007, to December 31, 2015. However, since January 1, 2016, a firework and cracker management policy has been implemented in Shanghai. We will continue to study the effects of these regulations on fireworks-related injuries.

Many previous studies have identified traumatic cataract as the most common complication of OGI, and some reports have indicated significant improvement in vision after surgical management following ocular trauma [33]. Compared with OGI in adults [34], pediatric OGI is less frequently caused by an intraocular foreign body, possibly because children are generally protected from hazardous work environments. A previous report [6] noted that work-related intraocular foreign body injuries affected 
up to $27.3 \%$ of adults. In contrast, in a previous study, we found that the incidence of intraocular foreign bodies in pediatric patients was $6.4 \%$ [27].

In the present study, we identified a significant association between the initial clinical presentation and visual acuity at hospital discharge. Consistent with previous studies [30,35], poor visual acuity at presentation, iridodialysis, and hyphema influenced visual recovery and had adverse effects on visual prognosis. The incidence of retinal detachment was similar to that reported in a previous study [27]. Some existing research has identified a significant association between visual prognosis and visual acuity in children [30] and adults [36, 37]. Tok et al. [30] previously reported that retinal detachment and endophthalmia were associated with a particularly poor prognosis. Some studies have also identified vitreous hemorrhage, endophthalmitis, and retinal detachment as predictors of poor prognosis [25]. Therefore, patients with iris prolapse, vitreous hemorrhage, retinal detachment, endophthalmia, or intraocular foreign body should be given intensive treatment to help salvage their vision.

This study included a very large number of cases and relatively comprehensive data, but there were several limitations related to the follow-up. First, we did not describe the zone of injury, which is an important factor in visual prediction, or the complications recorded in the initial findings by age group. Second, information about the surgical interventions used was recorded in a different system and was not included in this study. Third, although amblyopia is an important complication associated with pediatric ocular trauma, it was not included in the follow-up information. China does not have a perfected observation system for following up pediatric eye trauma. It is common for children to be examined and followed up in community health hospitals near their homes, because of economic limitations and transportation difficulties, especially those living in rural areas. We hope that, in the future, records can be linked between large specialized hospitals and community health hospitals, yielding a more complete information source.

\section{Conclusion}

In this study, we found that boys and preschool children were particularly vulnerable to OGI. Penetrating injuries were the most common injury type, and the objects causing OGI differed across the three age groups examined. Hyphema, iris prolapse, vitreous hemorrhage, retinal detachment, endophthalmia, intraocular foreign body, and an initial visual acuity of $<0.05$ were all associated with final VA. It is necessary to strengthen the recognition of specific hazards and to engage in public education about the prevention of eye trauma in children.

\section{Statement of Ethics}

This study protocol was reviewed and approved by the Ethics Committee of the EENT Hospital of Fudan University, approval number (No. 2019004). Signed informed consent was written from all their parents or guardians.

\section{Conflict of Interest Statement}

The authors have no conflicts of interest to declare.

\section{Funding Sources}

This study was funded by the Shanghai Committee of Science and Technology (Grant No. 16411953700, China; Grant No. 16401932500, China), the Youth Project of the National Natural Science Fund (81800846, 81700862, 82000918), Shanghai Sailing Program (20YF1404800), and the Study on the Comprehensive Prevention and Control of Common Eye Diseases in Xuhui District (XHLHGG201807).

\section{Author Contributions}

Y.G. and Yu.G. performed the study and wrote the paper; R.G., Q.Y., K.Z., and Q.S. performed the data analysis; D.G. designed and performed the study.

\section{Data Availability Statement}

The datasets used and/or analyzed in the current study are available from the corresponding author upon reasonable request.

\section{References}

1 Mir TA, Canner JK, Zafar S, Srikumaran D, Friedman DS, Woreta FA. Characteristics of open globe injuries in the United States from 2006 to 2014. JAMA Ophthalmol. 2020;138: $268-75$

2 Strahlman E, Elman M, Daub E, Baker S Causes of pediatric eye injuries. A population-based study. Arch Ophthalmol. 1990; 108:603-6.

3 Yildiz M, Kıvanç SA, Akova-Budak B, Ozmen AT, Çevik SG. An important cause of blindness in children: open globe injuries. J Ophthalmol. 2016;2016:7173515. 
4 Cao H, Li L, Zhang M, Li H. Epidemiology of pediatric ocular trauma in the Chaoshan region, China, 2001-2010. PLoS One. 2013;8: e60844.

5 Mader TH, Carroll RD, Slade CS, George RK, Ritchey JP, Neville SP. Ocular war injuries of the Iraqi Insurgency,January-September 2004. Ophthalmology. 2006;113:97-104.

6 Kanoff JM, Turalba AV, Andreoli MT, Andreoli CM. Characteristics and outcomes of work-related open globe injuries. Am J Ophthalmol. 2010;150:265-e2.

7 Kuhn F, Morris R, Witherspoon CD, Heimann K, Jeffers JB, Treister G. A standardized classification of ocular trauma. Graefes Arch Clin Exp Ophthalmol. 1996;234:399-403.

8 El-Sebaity DM, Soliman W, Soliman AM, Fathalla AM. Pediatric eye injuries in upper Egypt. Clin Ophthalmol. 2011;5:1417-23.

9 Liu ML, Chang YS, Tseng SH, Cheng HC, Huang FC, Shih MH, et al. Major pediatric ocular trauma in Taiwan. J Pediatr Ophthalmol Strabismus. 2010;47:88-95.

10 Serrano JC, Chalela P, Arias JD. Epidemiology of childhood ocular trauma in a northeastern Colombian region. Arch Ophthalmol. 2003;121:1439-45.

11 Gupta R, Gupta S, Chauhan L. Predicting visual outcome after open globe injury using classification and regression tree model: the Moradabad ocular trauma study. Can J Ophthalmol. 2019;54:473-8.

12 Court JH, Lu LM, Wang N, McGhee CNJ. Visual and ocular morbidity in severe openglobe injuries presenting to a regional eye centre in New Zealand. Clin Exp Ophthalmol. 2019;47:469-77.

13 Abbott J, Shah P. The epidemiology and etiology of pediatric ocular trauma. Surv Ophthalmol. 2013;58:476-85.

14 Beshay N, Keay L, Dunn H, Kamalden TA, Hoskin AK, Watson SL. The epidemiology of open globe injuries presenting to a tertiary referral eye hospital in Australia. Injury. 2017; 48:1348-54.

15 Guo Y, Liu Y, Xu H, Zhao Z, Gan D. Characteristics of paediatric patients hospitalised for eye trauma in 2007-2015 and factors related to their visual outcomes. Eye. $2021 \mathrm{Mar}$ 35(3): 945-51.
16 Kuhn F, Maisiak R, Mann L, Mester V, Morris $\mathrm{R}$, Witherspoon $\mathrm{CD}$. The ocular trauma score (OTS). Ophthalmol Clin North Am. 2002;15: 163-vi.

17 Batur M, Seven E, Akaltun MN, Tekin S, Yasar T. Epidemiology of open globe injury in children. J Craniofac Surg. 2017;28:1976-81.

18 Bourne RRA, Flaxman SR, Braithwaite T, Cicinelli MV, Das A, Jonas JB, et al. Magnitude, temporal trends, and projections of the global prevalence of blindness and distance and near vision impairment: a systematic review and meta-analysis. Lancet Glob Health. 2017;5: e888-97.

19 GBD 2019 Blindness and Vision Impairment Collaborators; Vision Loss Expert Group of the Global Burden of Disease Study. Causes of blindness and vision impairment in 2020 and trends over 30 years, and prevalence of avoidable blindness in relation to VISION 2020: the Right to Sight: an analysis for the Global Burden of Disease Study. Lancet Glob Health. 2021;9:e144-60.

20 Supreeyathitikul P, Chokesuwattanaskul S, Choovuthayakorn J, Patikulsila D, Watanachai N, Kunavisarut P, et al. Epidemiology and outcomes following open globe injury in agricultural region, an 11-year experience. Ophthalmic Epidemiol. 2020;27:246-51.

21 May DR, Kuhn FP, Morris RE, Witherspoon CD, Danis RP, Matthews GP, et al. The epidemiology of serious eye injuries from the United States eye injury registry. Graefes Arch Clin Exp Ophthalmol. 2000;238:153-7.

$22 \mathrm{Xu}$ YN, Huang YS, Xie LX. Pediatric traumatic cataract and surgery outcomes in eastern China: a hospital-based study. Int J Ophthalmol. 2013;6:160-4.

23 Toride A, Toshida H, Matsui A, Matsuzaki Y, Honda R, Ohta T, et al. Visual outcome after emergency surgery for open globe eye injury in Japan. Clin Ophthalmol. 2016;10:1731-6.

24 Al-Mahdi HS, Bener A, Hashim SP. Clinical pattern of pediatric ocular trauma in fast developing country. Int Emerg Nurs. 2011;19: 186-91.

25 Lee CH, Lee L, Kao LY, Lin KK, Yang ML. Prognostic indicators of open globe injuries in children. Am J Emerg Med. 2009;27:530-5.

26 Gunes A, Kalayc M, Genc O, Ozerturk Y. Characteristics of open globe injuries in preschool children. Pediatr Emerg Care. 2015;31: 701-3.
27 AlDahash F, Mousa A, Gikandi PW, Abu EA. Pediatric open-globe injury in a universitybased tertiary hospital. Eur J Ophthalmol. 2020;30:269-74.

28 Sun Z, Zhuang X, Xu G, Jiang R. Clinical analysis of posterior segment injury in left-behind children in China. BMC Ophthalmol. 2020; 20:40.

29 Guven S, Durukan AH, Erdurman C, Kucukevcilioglu M. Prognostic factors for openglobe injuries: variables for poor visual outcome. Eye. 2019;33:392-7.

30 Tok O, Tok L, Ozkaya D, Eraslan E, Ornek F, Bardak Y. Epidemiological characteristics and visual outcome after open globe injuries in children. J AAPOS. 2011;15:556-61.

31 Sundelin K, Norrsell K. Eye injuries from fireworks in Western Sweden. Acta Ophthalmol Scand. 2000;78:61-4.

32 Ferguson RA, Sung J, McKelvie J. New Zealand childhood ocular trauma study: analysis of 75,601 cases of ocular injury from 2007 to 2016. Clin Exp Ophthalmol. 2019;47:718-25.

33 Shah MA, Shah SM, Gosai SR, Gupta SS, Khanna RR, Patel KB, et al. Comparative study of visual outcome between open- and closed-globe injuries following surgical treatment of traumatic cataract in children. Eur J Ophthalmol. 2018;28:406-11.

34 Fu R, Kancherla S, Eller AW, Yu JY. Characteristics and outcomes of open globe trauma in the urban versus rural population: a single center retrospective review. Semin Ophthalmol. 2018;33:566-70.

35 Dandona L, Dandona R, Srinivas M, John RK, McCarty CA, Rao GN. Ocular trauma in an urban population in southern India: the Andhra Pradesh eye disease study. Clin Exp Ophthalmol. 2000;28:350-6.

36 Wang W, Zhou Y, Zeng J, Shi M, Chen B. Epidemiology and clinical characteristics of patients hospitalized for ocular trauma in South-Central China. Acta Ophthalmol. 2017;95:e503-10.

37 Fujikawa A, Mohamed YH, Kinoshita $\mathrm{H}$, Matsumoto M, Uematsu M, Tsuiki E, et al. Visual outcomes and prognostic factors in open-globe injuries. BMC Ophthalmol. 2018; $18: 138$ 